\title{
Processing issues and their influence in the magnetoelectric performance of $(\mathrm{K}, \mathrm{Na}) \mathrm{NbO}_{3} / \mathrm{CoFe}_{2} \mathrm{O}_{4}$-based layered composites
}

\author{
Washington Santa Rosa ${ }^{\mathrm{a}}$, Michel Venet ${ }^{\mathrm{a}}$, Jean-Claude M'Peko ${ }^{\mathrm{b}}$, Harvey \\ Amorín ${ }^{\mathrm{c}}$, Miguel Algueróc,* \\ ${ }^{a}$ Departamento de Física, Universidade Federal de São Carlos, 13565-905, São Carlos, \\ SP, Brazil. \\ ${ }^{b}$ Instituto de Física de São Carlos, Universidade de São Paulo, 13560-970, São Carlos, \\ SP, Brazil. \\ ${ }^{c}$ Instituto de Ciencia de Materiales de Madrid, CSIC. Cantoblanco, 28049 Madrid, \\ Spain.
}

\begin{abstract}
Low temperature processing of environmentally-friendly $(\mathrm{K}, \mathrm{Na}) \mathrm{NbO}_{3}$ and $\mathrm{CoFe}_{2} \mathrm{O}_{4}$-based layered composites has been accomplished by hot pressing, and their electrical, piezoelectric and magnetoelectric properties have been characterized. High quality composite three-layer $\mathrm{CoFe}_{2} \mathrm{O}_{4} / \mathrm{K}_{0.5} \mathrm{Na}_{0.5} \mathrm{NbO}_{3} / \mathrm{CoFe}_{2} \mathrm{O}_{4}$ structures with defect-free interfaces have been obtained by hot pressing at only $1000{ }^{\circ} \mathrm{C}$, when highly reactive $\mathrm{CoFe}_{2} \mathrm{O}_{4}$ powders obtained by Pechini are used. Negligible chemical reactions at, and interdiffusion across interfaces take place during the low temperature processing, while alkali volatilization is also minimized. Dense, crack-free $\mathrm{CoFe}_{2-z} \mathrm{Ga}_{z} \mathrm{O}_{4} /\left(\mathrm{K}_{0.5} \mathrm{Na}_{0.5}\right)_{1-x} \mathrm{Li}_{x} \mathrm{Nb}_{1-y} \mathrm{Ta}_{y} \mathrm{O}_{3} / \mathrm{CoFe}_{2-z} \mathrm{Ga}_{z} \mathrm{O}_{4}$ structures incorporating phases with enhanced piezoresponse have been also obtained,
\end{abstract}

\footnotetext{
${ }^{*}$ Corresponding author

Email address: malguero@icmm.csic.es (Miguel Algueró)
} 
though in this case both piezoelectric and magnetoelectric coefficients steadily increase with the hot pressing temperature up to $1100{ }^{\circ} \mathrm{C}$. This is shown to be related with the presence of core-shell type microstructure within the piezoelectric layer characteristic of $\left(\mathrm{K}_{0.5} \mathrm{Na}_{0.5}\right)_{1-x} \mathrm{Li}_{x} \mathrm{Nb}_{1-y} \mathrm{Ta}_{y} \mathrm{O}_{3}$, and that is stabilized by the low temperature processing. Procedures for further enhancement of the magnetoelectric response are proposed.

Keywords: Magnetoelectric, KNN, Lead free, Layered composites, Cobalt ferrite

\section{Introduction}

Cofired ceramic composites of high sensitivity piezoelectric perovskite and magnetostrictive spinel oxides are concentrating an increasing attention, for they are key enabling materials for the mass production and miniaturization of a range of demonstrated magnetoelectric technologies, such as electrically tunable magnetic devices for microwave communications [1], high sensitivity magnetic field sensors with room temperature operation [2], and wireless, remotely- or self-rechargeable powering technologies with/from magnetic fields $[3,4]$.

These technologies make use of the composite ability of developing a linear electrical polarization in response to a magnetic field (direct magnetoelectric effect), and of a magnetization in response of an electric one (converse effect). This is accomplished by means of strain mediation, so that when a magnetic (electric) field $\mathrm{H}$ (E) is applied, the magnetostrictive (piezoelectric) phase deforms. Strain (S) then is transmitted to the piezoelectric (magnetostrictive) phase that develops an electric polarization (magnetization) $\mathrm{P}(\mathrm{M})$ [5-7]. 
Best results have been obtained for laminate composites of $\mathrm{Pb}(\mathrm{Zr}, \mathrm{Ti}) \mathrm{O}_{3^{-}}$ (PZT) and $\mathrm{NiFe}_{2} \mathrm{O}_{4}$-based compositions, for which voltage transverse magnetoelectric coefficients $\alpha_{31}^{E}$ as large as $\sim 500 \mathrm{mVcm}^{-1} \mathrm{Oe}^{-1}$ have been obtained in two-layer and three-layer structures that were enhanced up to 1.5 $\mathrm{Vcm}^{-1} \mathrm{Oe}^{-1}$ with multilayer structures [8-10]. However, currently enforced environmental regulations worldwide like EU-Directive 2002/95/EC (RoHS) require the restriction of the use of lead, among a list of hazardous substances, in electrical and electronic equipment. This has fostered the search of leadfree alternatives to PZT-based state-of-the-art commercial high sensitivity piezoceramics $[11,12]$.

A highly topical group of materials are $\left(\mathrm{Bi}_{1 / 2} \mathrm{Na}_{1 / 2}\right) \mathrm{TiO}_{3}$-based solid solutions, such as $\left(\mathrm{Bi}_{1 / 2} \mathrm{Na}_{1 / 2}\right) \mathrm{TiO}_{3}-\mathrm{BaTiO}_{3}-\mathrm{K}_{0.5} \mathrm{Na}_{0.5} \mathrm{NbO}_{3}$ and $\left(\mathrm{Bi}_{1 / 2} \mathrm{Na}_{1 / 2}\right) \mathrm{TiO}_{3^{-}}$ $\left(\mathrm{Bi}_{1 / 2} \mathrm{~K}_{1 / 2}\right) \mathrm{TiO}_{3}$ that show very large electric field induced strain, and are thus specially suitable for actuation $[13,14]$. Although piezoelectric charge coefficients are below those of PZT, the processing of particulate composites was recently addressed, and a magnetoelectric coefficient of $40 \mathrm{mVcm}^{-1} \mathrm{Oe}^{-1}$ was reported for $\mathrm{Bi}_{0.5} \mathrm{Na}_{0.4} \mathrm{~K}_{0.1} \mathrm{TiO}_{3}-\mathrm{Ni}_{0.8} \mathrm{Zn}_{0.2} \mathrm{Fe}_{2} \mathrm{O}_{4}$ [15]. Piezoelectric charge coefficients comparable to best PZTs have been obtained for materials in the $(\mathrm{Ba}, \mathrm{Ca}) \mathrm{TiO}_{3}-\mathrm{Ba}(\mathrm{Ti}, \mathrm{Zr}) \mathrm{O}_{3}$ system [16], and particulate composites of $\mathrm{Ba}_{0.85} \mathrm{Ca}_{0.15} \mathrm{Ti}_{0.9} \mathrm{Zr}_{0.1} \mathrm{O}_{3}$ and $\mathrm{Ni}_{0.8} \mathrm{Zn}_{0.2} \mathrm{Fe}_{2} \mathrm{O}_{4}$ have also been recently reported. A magnetoelectric coefficient of $13 \mathrm{mVcm}^{-1} \mathrm{Oe}^{-1}$ was achieved in this case [17].

Nevertheless, most promising materials for replacing PZTs are $(\mathrm{K}, \mathrm{Na}) \mathrm{NbO}_{3}$-based compositions, like $\left(\mathrm{K}_{0.5} \mathrm{Na}_{0.5}\right)_{1-x} \mathrm{Li}_{x}\left(\mathrm{Nb}_{1-y} \mathrm{Ta}_{y}\right) \mathrm{O}_{3}$ and $\left(\mathrm{K}_{0.5} \mathrm{Na}_{0.5}\right)_{1-x} \mathrm{Li}_{x}\left(\mathrm{Nb}_{1-y-z} \mathrm{Ta}_{y} \mathrm{Sb}_{z}\right) \mathrm{O}_{3}$ ones [18]. Particulate composites of 
$\left(\mathrm{K}_{0.5} \mathrm{Na}_{0.5}\right)_{0.948} \mathrm{Li}_{0.052} \mathrm{Nb}_{0.948} \mathrm{Sb}_{0.052} \mathrm{O}_{3}$ and $\mathrm{Ni}_{0.8} \mathrm{Zn}_{0.2} \mathrm{Fe}_{2} \mathrm{O}_{4}$ with a magnetoelectric coefficient of $20 \mathrm{mVcm}^{-1} \mathrm{Oe}^{-1}$ have been reported [19], while a magnetoelectric coefficient $\alpha_{31}^{E}$ of $\sim 130 \mathrm{mVcm}^{-1} \mathrm{Oe}^{-1}$ was obtained in laminate composites of $\left(\mathrm{K}_{0.45} \mathrm{Na}_{0.55}\right)_{0.98} \mathrm{Li}_{0.02} \mathrm{Nb}_{0.77} \mathrm{Ta}_{0.18} \mathrm{Sb}_{0.05} \mathrm{O}_{3}$ and $\mathrm{Ni}_{0.37} \mathrm{Cu}_{0.20} \mathrm{Zn}_{0.43} \mathrm{Fe}_{1.92} \mathrm{O}_{3.88}$ [20]. It is well known that, even though theory does not anticipate 2-2 phase connectivity to provide a larger response than the 3-0 one [5], it highly facilitates phase geometric assemblage and the piezoelectric poling, so that higher magnetoelectric coefficients are consistently attained [20-22]. Although the former $\alpha_{31}^{E}$ coefficient is the largest figure achieved for a lead-free magnetoelectric composite up to now, the presence of other highly toxic species like $\mathrm{Sb}$ and $\mathrm{Ni}$ turns this system into one not environmentally friendly [11]. Removal of Sb does not present serious challenges, for high piezoelectric coefficients have also been reported for $\left(\mathrm{K}_{0.5} \mathrm{Na}_{0.5}\right)_{1-x} \mathrm{Li}_{x} \mathrm{Nb}_{1-y} \mathrm{Ta}_{y} \mathrm{O}_{3}$ compositions like that with $\mathrm{x}=0.03$ and $\mathrm{y}=0.20$ [18]. However, replacement of $\mathrm{NiFe}_{2} \mathrm{O}_{4}$ is more challenging, because alternative spinel oxides like $\mathrm{CoFe}_{2} \mathrm{O}_{4}$ show enhanced magnetocrystalline anisotropy and coercive field. This results in a reduced rate of change of magnetostriction with applied magnetic field and thus, of effective piezomagnetic coefficients under bias, even if the total magnetostriction of $\mathrm{CoFe}_{2} \mathrm{O}_{4}$ is larger than that of $\mathrm{NiFe}_{2} \mathrm{O}_{4}$. Indeed, studies of composite processing incorporating $\mathrm{CoFe}_{2} \mathrm{O}_{4}$-based compositions always resulted in magnetoelectric coefficients lower than works using $\mathrm{NiFe}_{2} \mathrm{O}_{4}$ [23-25]. Besides, $\mathrm{CoFe}_{2} \mathrm{O}_{4}$ sintering requires temperatures above $1100{ }^{\circ} \mathrm{C}$, at which $(\mathrm{K}, \mathrm{Na}) \mathrm{NbO}_{3}$-based compositions suffer the loss of alkali chemical species [26]. This highly complicates co-sintering. 
We present here results of our investigation on the low temperature processing of composite layered structures of $\left(\mathrm{K}_{0.5} \mathrm{Na}_{0.5}\right)_{1-x} \mathrm{Li}_{x} \mathrm{Nb}_{1-y} \mathrm{Ta}_{y} \mathrm{O}_{3}$ and $\mathrm{CoFe}_{2-z} \mathrm{Ga}_{z} \mathrm{O}_{4}$. Ga substitution for $\mathrm{Fe}$ in $\mathrm{CoFe}_{2} \mathrm{O}_{4}$ has been demonstrated to be an effective means of reducing the magnetocrystalline anisotropy, and to provide an enhanced rate of change of magnetostriction with applied magnetic field [27]. Hot pressing combined with the use of highly reactive nanocrystalline $\mathrm{CoFe}_{2} \mathrm{O}_{4}$ powders are investigated here as a means of enabling co-sintering. This pressure assisted sintering technique has been successfully applied to the processing of cofired $\mathrm{Pb}(\mathrm{Zr}, \mathrm{Ti}) \mathrm{O}_{3}-\mathrm{NiFe}_{2} \mathrm{O}_{4}$ particulate composites at reduced temperatures [28]. A number of processing issues specific of the $\left(\mathrm{K}_{0.5} \mathrm{Na}_{0.5}\right)_{1-x} \mathrm{Li}_{x} \mathrm{Nb}_{1-y} \mathrm{Ta}_{y} \mathrm{O}_{3}-\mathrm{CoFe}_{2-z} \mathrm{Ga}_{z} \mathrm{O}_{4}$ system are revealed, whose influence in the magnetoelectric response is thoroughly discussed.

\section{Experimental}

$\mathrm{K}_{0.5} \mathrm{Na}_{0.5} \mathrm{NbO}_{3}(\mathrm{KNN})$ and $\left(\mathrm{K}_{0.5} \mathrm{Na}_{0.5}\right)_{1-x} \mathrm{Li}_{x} \mathrm{Nb}_{1-y} \mathrm{Ta}_{y} \mathrm{O}_{3}$ (KNLNT) powders were synthesized by solid state reaction of stoichiometric mixtures of high purity $\mathrm{K}_{2} \mathrm{CO}_{3}, \mathrm{Na}_{2} \mathrm{CO}_{3}, \mathrm{Li}_{2} \mathrm{CO}_{3}, \mathrm{Nb}_{2} \mathrm{O}_{5}$ and $\mathrm{Ta}_{2} \mathrm{O}_{5}$. A thermal treatment at $600{ }^{\circ} \mathrm{C}$ for $10 \mathrm{~h}$ with $5{ }^{\circ} \mathrm{Cmin}^{-1}$ heating rate was used in the case of $\mathrm{KNN}$, while two successive calcinations at $750{ }^{\circ} \mathrm{C}$ and $800{ }^{\circ} \mathrm{C}$ for $5 \mathrm{~h}$ were carried out in the case of KNLNT, with intermediate attrition milling for $24 \mathrm{~h}$ to increase chemical homogeneity [29, 30]. Four KNLNT compositions were prepared: (i) $\mathrm{x}=0.03$ and $\mathrm{y}=0.20$ (hereinafter referred as L3T20), (ii) $\mathrm{x}=0.035$ and $\mathrm{y}=0.20$ (L3.5T20), (iii) $\mathrm{x}=0.04$ and $\mathrm{y}=0.20$ (L4T20), and (iv) $\mathrm{x}=0.04$ and $\mathrm{y}=0.15$ (L4T15). Composition L3T20 is the LF3 material high- 
lighted in [18] as a viable alternative to replace PZT based materials, while composition L4T20 has been shown to present even higher piezoelectric coefficients in our recent study that explored compositions around $\mathrm{x}=0.03$ and $\mathrm{y}=0.20$ [31]. In the same work, Li4T15/CFO composites were anticipated to present the highest $\alpha_{31}^{E}$ among a range of KNLNT/CFO layered structures. Finally, composition L3.5T20 was included in order to facilitate the analysis of the role of Li content.

$\mathrm{CoFe}_{2} \mathrm{O}_{4}(\mathrm{CFO})$ and $\mathrm{CoFe}_{1.85} \mathrm{Ga}_{0.15} \mathrm{O}_{4}$ (CFG15) powders were firstly synthesized by solid state reaction of stoichiometric mixtures of high purity $\mathrm{Co}_{3} \mathrm{O}_{4}, \mathrm{Fe}_{2} \mathrm{O}_{3}$ and $\mathrm{Ga}_{2} \mathrm{O}_{3}$. Synthesis conditions were taken from literature [32]. Specifically, a two-step calcination process involving thermal treatments at $900{ }^{\circ} \mathrm{C}$ and $1000{ }^{\circ} \mathrm{C}$ for $12 \mathrm{~h}$ was used. $\mathrm{CoFe}_{1.85} \mathrm{Ga}_{0.15} \mathrm{O}_{4}$ was chosen among the different $\mathrm{CoFe}_{2-z} \mathrm{Ga}_{z} \mathrm{O}_{4}$ phases, for a previous investigation showed it to have the highest rate of change of magnetostriction with applied magnetic field [33]. Powders were also alternative synthesized by a Pechini method where the starting materials $\mathrm{Fe}\left(\mathrm{NO}_{3}\right)_{3}, \mathrm{Co}\left(\mathrm{NO}_{3}\right)_{3}$ and $\mathrm{Ga}\left(\mathrm{NO}_{3}\right)_{3}$ were dissolved in distilled water and citric acid in proper stoichiometric proportions. Citric acid in 1:3 M ratio with respect to metal nitrates was used. Subsequently, ethylene glicol was added in 2:3 ratio with respect to the acid. The sol was then heated at $90{ }^{\circ} \mathrm{C}$ until its complete transformation into a gel. Finally, the obtained gel was dried at $300{ }^{\circ} \mathrm{C}$ for $4 \mathrm{~h}$, and thermally treated at $600{ }^{\circ} \mathrm{C}$ for $1 \mathrm{~h}$ to obtain the spinel oxide.

Green pellets of the piezoelectric and magnetostrictive oxide powders, and three-layer magnetostrictive/piezoelectric/magnetostrictive stacks were obtained by uniaxial pressing. Hot pressing of the green bodies was carried 
out at temperatures between 800 and $1100{ }^{\circ} \mathrm{C}$ at a pressure of $60 \mathrm{MPa}$, with $+3 /-1^{\circ} \mathrm{C} \min ^{-1}$ heating/cooling rates. A soaking time of $1 \mathrm{~h}$ was selected. Ceramic density was evaluated by the Archimedes' method, and densification levels were obtained with the crystallographic density determined from the cell parameters (derived from X-ray diffraction data). Actual volume fractions of the perovskite and spinel oxide phases were taken into account in the case of the composite three-layer structures that were $1 / 3$ and $2 / 3$, respectively (single layer thickness of $1 \mathrm{~mm}$ and disc diameter of $12 \mathrm{~mm}$ ).

Ceramic microstructures and composite interface quality were characterized by field-emission scanning electron microscopy with a FEI Nova NanoSEM 230 apparatus on cross section specimens of the three-layer structures cut perpendicular to the stacking plane. Samples were prepared by polishing with $\mathrm{Al}_{2} \mathrm{O}_{3}$ suspensions down to $0.1 \mu \mathrm{m}$.

Ceramic capacitors for the electrical characterization of the piezoelectric material and of the composite three-layer structures were prepared by painting of $\mathrm{Ag}$ electrodes on the major faces, and their sintering at $700{ }^{\circ} \mathrm{C}$. The temperature dependences of the dielectric permittivity and losses were measured between room temperature (RT) and $550{ }^{\circ} \mathrm{C}$ with a $\mathrm{HP} 4284 \mathrm{~A}$ precision LCR meter. Measurements were dynamically carried out during a heating/cooling cycle with $1.5^{\circ} \mathrm{Cmin}^{-1}$ rate at several frequencies between $100 \mathrm{~Hz}$ and $1 \mathrm{MHz}$. RT ferroelectric hysteresis loops were recorded under voltage sine waves of increasing amplitude up to $10 \mathrm{kV}$ with a $0.1 \mathrm{~Hz}$ frequency, obtained by the combination of a synthesizer/function generator (HP 3325B) and a high voltage amplifier (TREK model 10/40), while charge was measured with a homebuilt charge to voltage converter and software for loop 
acquisition and analysis.

Subsequently, piezoelectric ceramics and composite three-layer structures were poled for piezoelectric characterization. Optimum conditions for each system were defined by applying increasing fields at temperatures between RT and $100{ }^{\circ} \mathrm{C}$ (selected by presenting leakage currents below a threshold), until saturation of the piezoelectric charge longitudinal coefficient $d_{33}$ was attained as measured with a Berlincourt type meter $24 \mathrm{~h}$ after the poling step.

Finally, the magnetoelectric response of the composite three-layer structures was characterized. A system comprising a combination of one electromagnet and one Helmholtz coil, designed to independently provide a static magnetic field up to $10 \mathrm{kOe}$ to magnetize the material, and an alternate magnetic field of $30 \mathrm{Oe}$ at $25 \mathrm{~Hz}$ that plays as stimulus was used, while the magnetoelectric voltage response was monitored with a lock-in amplifier. A 3-1 geometry was chosen to obtain the transverse magnetoelectric coefficient $\alpha_{31}^{E}$ as a function of the bias magnetic field $\mathrm{H}$, after normalization to the piezoelectric element thickness.

Additionally, the electrical conductivity of the magnetostrictive material was characterized, for which Ag electrodes were also painted on ceramic samples of the spinel oxide. Impedance spectroscopy analysis was accomplished. Measurements were carried out in static conditions, from 250 to $550{ }^{\circ} \mathrm{C}$, at $20{ }^{\circ} \mathrm{C}$ intervals, in the $20 \mathrm{~Hz}-1 \mathrm{MHz}$ range with the $\mathrm{HP} 4284 \mathrm{~A}$ precision LCR meter. The Z-view2 commercial software was used for the analysis. 


\section{Results and Discussion}

Results are presented and discussed in four sections. Hot pressing studies of the piezoelectric and magnetostrictive oxide powders, accomplished in order to define the temperature range, in which composite structures could be processed, are firstly shown. This is followed by two successive sections, where the microstructure and properties of the $\mathrm{K}_{0.5} \mathrm{Na}_{0.5} \mathrm{NbO}_{3} / \mathrm{CoFe}_{2} \mathrm{O}_{4}$ and $\left(\mathrm{K}_{0.5} \mathrm{Na}_{0.5}\right)_{1-x} \mathrm{Li}_{x} \mathrm{Nb}_{1-y} \mathrm{Ta}_{y} \mathrm{O}_{3} / \mathrm{CoFe}_{1.85} \mathrm{Ga}_{0.15} \mathrm{O}_{4}$ layered composites are comprehensively presented. Main composite effects are established. Finally, a wrap-up section is included, in which processing issues are raised, and their relationship to functionality are defined. Implications in the low temperature processing of KNN/CFO based layered composites are also analyzed.

\subsection{Hot pressing of piezoelectric and magnetostrictive oxide powders}

Hot pressing studies were carried out with the piezoelectric and magnetostrictive oxide powders to determine the temperature range, in which dense materials could be obtained. Results for the KNN- and CFO-based compositions are summarized in Fig. 1.

On the one hand, pressure-assisted sintering enabled obtaining KNN with a densification of $97 \%$ at only $800{ }^{\circ} \mathrm{C}$, which increased up to $98.5 \%$ at 900 ${ }^{\circ} \mathrm{C}$. Nonetheless, a lower densification of $95.5 \%$ resulted at $1000{ }^{\circ} \mathrm{C}$, which strongly suggests microstructural degradation to have been triggered at this temperature, most probably associated with the onset of alkali (and mainly $\mathrm{Na}$ ) volatilization. KNLT compositions did not attain densifications above $95 \%$ until $100{ }^{\circ} \mathrm{C}$, and maintained levels between 96 and $98 \%$ after hot pressing at 1050 and $1100{ }^{\circ} \mathrm{C}$. On the other hand, hot pressing of conventional 

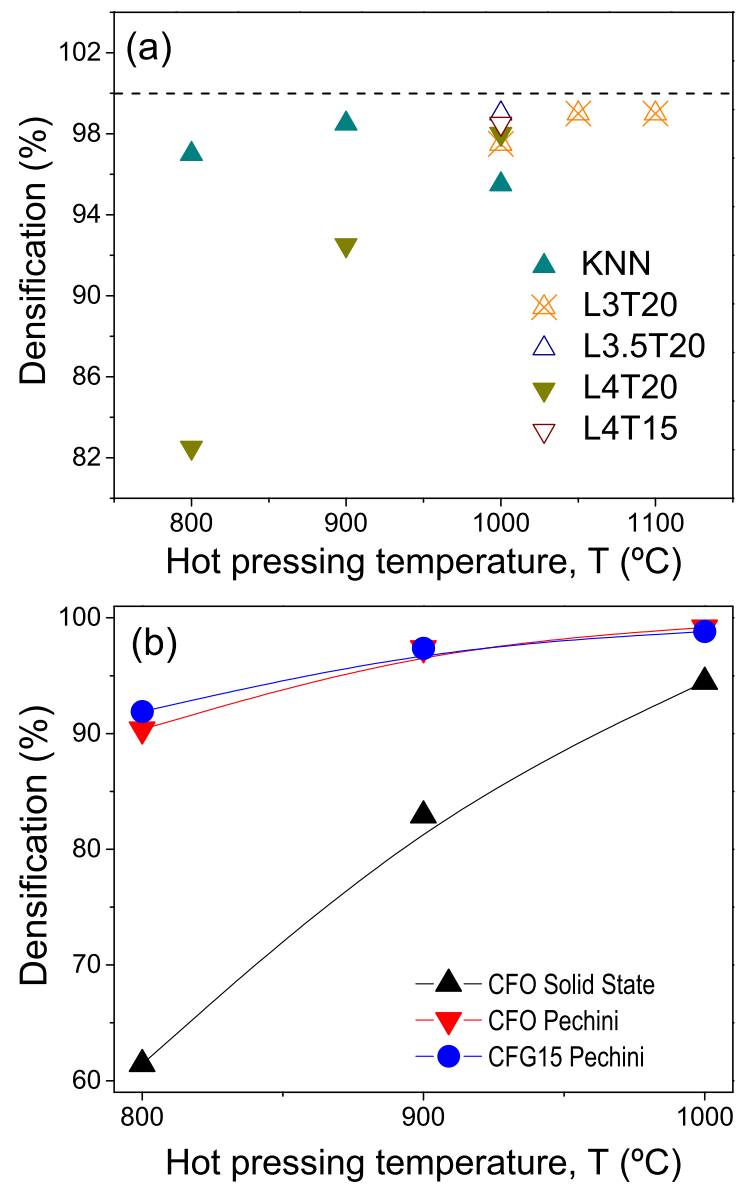

Fig. 1. Hot pressing temperature dependence of the densification of ceramic materials of (a) KNN-based and (b) CFO-based compositions, prepared from different source powders.

CFO powders obtained by solid state reactions resulted in comparatively low densifications that hardly reached $90 \%$ at $1000{ }^{\circ} \mathrm{C}$. This is why the highly reactive powders prepared by Pechini were alternatively used. Densifications above $95 \%$ were obtained in this case, both for CFO and CFG15, as illustrated in Fig. 1b.

Overall, these hot pressing studies indicated that $1000{ }^{\circ} \mathrm{C}$ was the lowest temperature for the co-firing of the two oxide powders under pressure. 
Therefore, this temperature was selected as a starting point for the processing of the composite layered structures, with the objective of minimizing possible chemical reactions at and interdiffusion across the interfaces, and of suppressing alkali volatilization. Hot pressing does not allow carrying out sintering in $\mathrm{Na}_{2} \mathrm{O}$ and $\mathrm{K}_{2} \mathrm{O}$ saturated atmospheres, which is the standard procedure to control alkali volatilization during conventional sintering at higher temperatures [26].

\section{2. $\mathrm{K}_{0.5} \mathrm{Na}_{0.5} \mathrm{NbO}_{3} / \mathrm{CoFe}_{2} \mathrm{O}_{4}$ layered composites}

Initial hot pressing experiments with the three-layer $\mathrm{CoFe}_{2} \mathrm{O}_{4}$ / $\mathrm{K}_{0.5} \mathrm{Na}_{0.5} \mathrm{NbO}_{3} / \mathrm{CoFe}_{2} \mathrm{O}_{4}$ stacks revealed temperature at which pressure was released as a key parameter to obtain high quality composites, free of microcracking. Indeed, full composite disintegration occurred when pressure was released at high temperature, and a continuous improvement of mechanical performance and final magnetoelectric response resulted when pressure was maintained during cooling until decreasing temperatures. Therefore, optimized materials were those, for which pressure was applied once the targeted temperature was reached, and released at room temperature after cooling had ended.

A scanning electron microscopy image of an interface for an optimized material processed at $1000{ }^{\circ} \mathrm{C}$ is shown in Fig. 2, along with images of the ceramic microstructure of the piezoelectric and magnetostrictive oxides. It is remarkable the quality of the interface, which is free of microstructural defects or second phases. This demonstrates that hot pressing is an effective means of minimizing chemical reaction at and interdiffusion across the interfaces. Microstructural gradients do not exist either, and similarly dense 
microstructures were found all across the composite with no variations of grain size that is of the order of the micron in the case of KNN, and much finer, within the submicron range in the case of CFO (note the different scales in Fig. 2a and 2c).
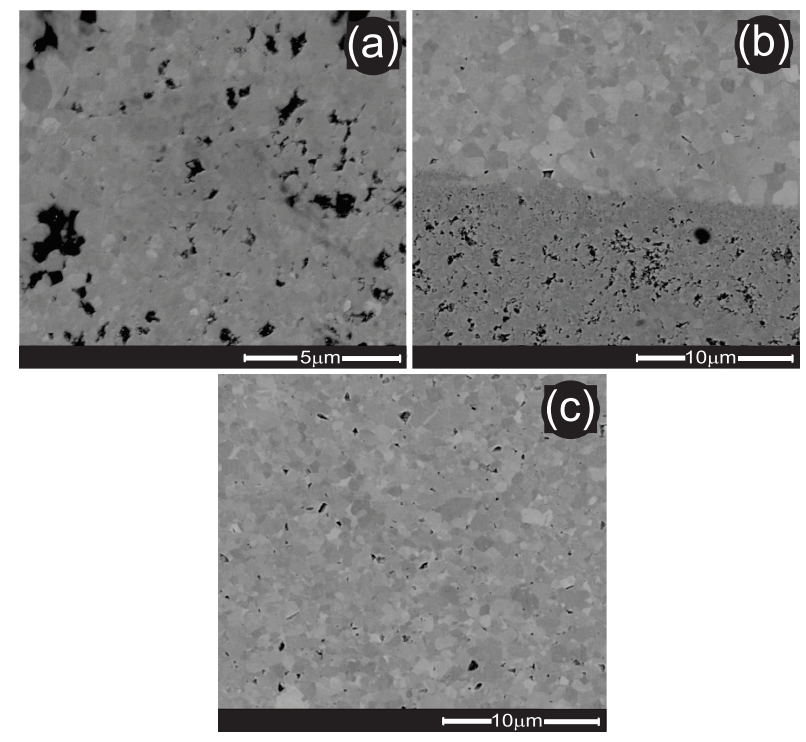

Fig. 2. Scanning electron microscopy images across a KNN/CFO layered composite processed by hot pressing at $1000{ }^{\circ} \mathrm{C}$ : (a) $\mathrm{CFO}$ microstructure, (b) $\mathrm{CFO} / \mathrm{KNN}$ interface, (c) KNN microstructure.

The high quality of the composite structures enabled a sound electrical characterization to be carried out. Results are shown in Fig. 3, 4, 5 and 6, where the properties of the three-layer structures are compared with those of KNN piezoelectric ceramics analogously processed. The temperature dependence of the relative permittivity is shown in Fig. 3 at five frequencies. Response at $1 \mathrm{kHz}$ is highlighted in the insets. The characteristic dielectric anomalies associated with the ferroelectric transition at $\sim 430{ }^{\circ} \mathrm{C}$ and the polymorphic phase transition between the tetragonal and orthorhombic 
ferroelectric phases at $\sim 215^{\circ} \mathrm{C}$ are easily identified in the response of the piezoceramic, and also in that of the composite at the same temperatures. Only difference between the two materials is the presence of an additional step-like increase of permittivity at intermediate temperatures in the case of the composite, whose height decreases as frequency increases, while its positions shifts toward higher temperatures. Corresponding loss tangent values are shown in Fig. 4. A distinctive peak in losses is associated with the highly dispersive step, whose position also shifts toward higher temperatures with frequency. The dispersive loss peak is not present in the case of the piezoceramic as shown in the inset of Fig. $4 \mathrm{~b}$.

This behaviour has widely been observed in layered composites, and it has been associated with a Maxwell-Wagner type relaxation originating from the difference in conductivity between the piezoelectric perovskite and magnetostrictive spinel oxides [34]. Indeed, if one carries out an Arrhenius type analysis with the relaxation times associated with the loss peak (from its position in temperature as a function of frequency), an activation energy of $0.52 \mathrm{eV}$ is obtained as illustrated in Fig. 5. This value is basically the activation energy of the conductivity of $\mathrm{CFO}$ at intermediate temperatures, as also shown in the Figure. See the Arrhenius plot in Fig. 5b that corresponds to the conductivity of an analogously processed CFO ceramic.

Room temperature ferroelectric hysteresis loops for the composite threelayer structure and for an analogously processed piezoceramic are shown in Fig. 6. Saturation of remnant polarization $P_{R}$ is apparently approached in the case of the composite at an electric field $E_{m}$ of $4 \mathrm{kVmm}^{-1}$, with values of $P_{R}$ and coercive field $E_{C}$ of $21.5 \mu \mathrm{Ccm}^{-2}$ and $2.7 \mathrm{kVmm}^{-1}$, respectively. 


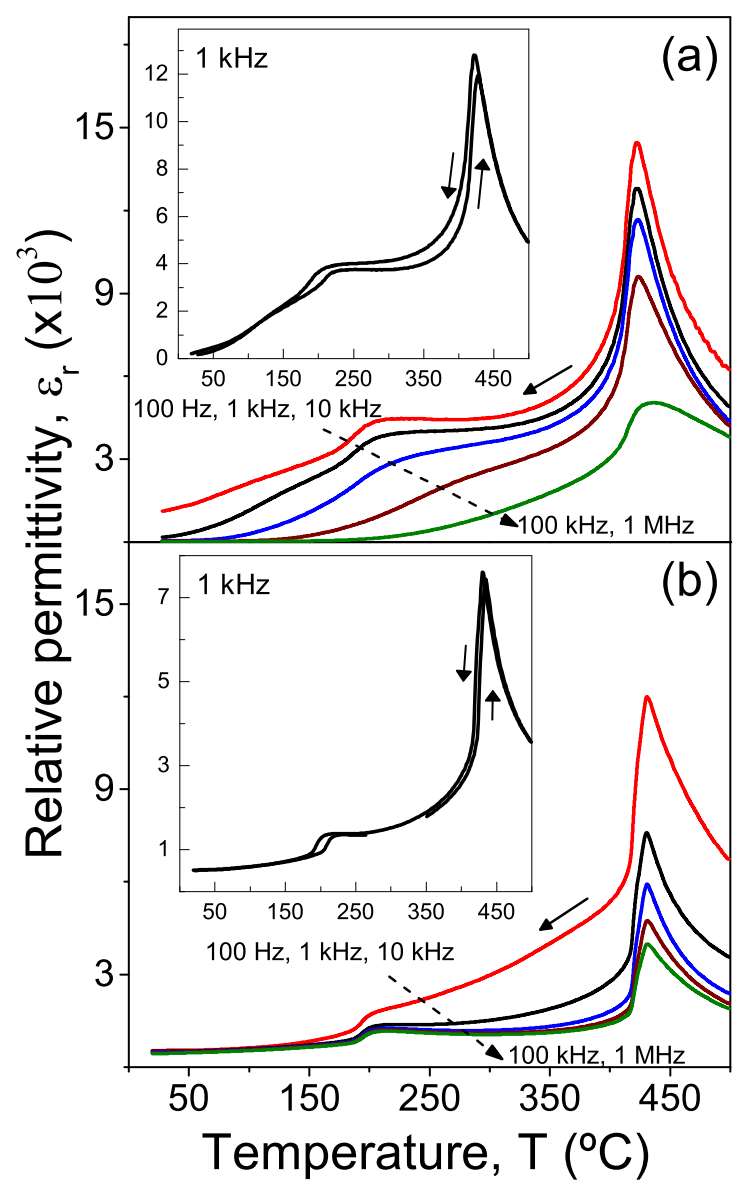

Fig. 3. Temperature and frequency dependences of the relative permittivity of (a) a $\mathrm{CFO} / \mathrm{KNN} / \mathrm{CFO}$ three-layer structure, and (b) a KNN ceramic, both processed by hot pressing at $1000{ }^{\circ} \mathrm{C}$. Response at $1 \mathrm{kHz}$ is separately shown in the insets.

However, the maximum applied field $E_{m}$ is far from $2.5 E_{C}$ (usually requested for assuming saturation), and besides $E_{C}$ keeps increasing with field, which is also an indication of lack of saturation. The composite coercive field is significantly higher than that of a KNN ceramic at the same $E_{m}$ that was only $1.2 \mathrm{kVmm}^{-1}$. This is most probably an effect of the presence of the CFO two layers in series with the KNN one that have larger capacitive impedances and 


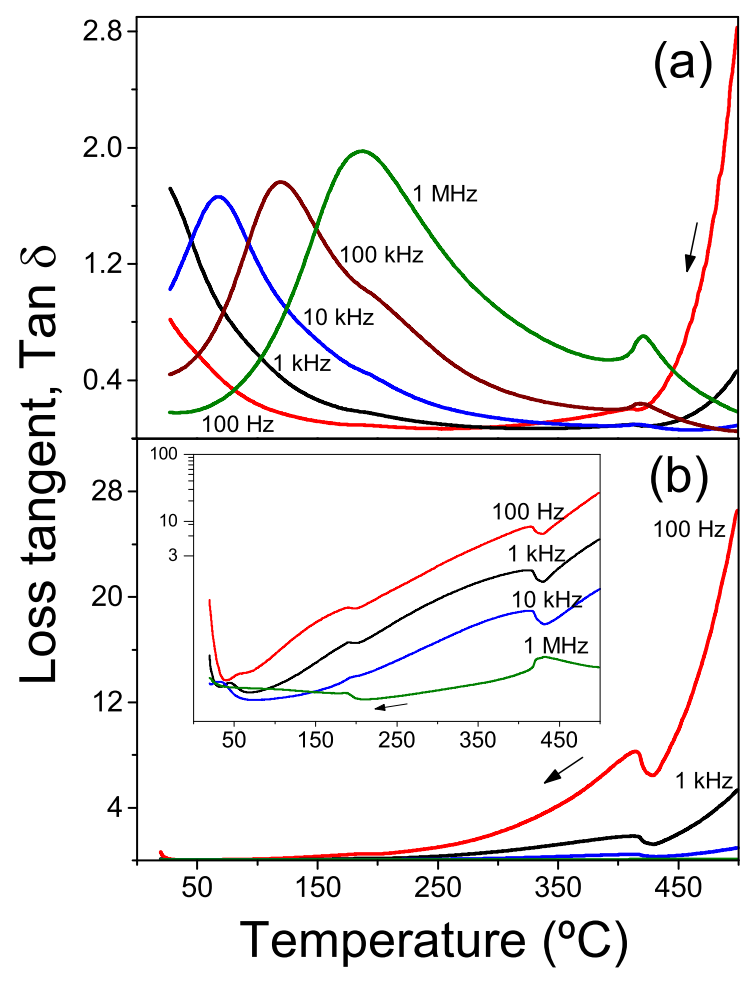

Fig. 4. Temperature and frequency dependences of the loss tangent of (a) a $\mathrm{CFO} / \mathrm{KNN} / \mathrm{CFO}$ three-layer structure, and (b) a KNN ceramic, both processed by hot pressing at $1000{ }^{\circ} \mathrm{C}$. Low temperature dispersion is highlighted in the inset for the piezoceramic.

thus, causes a decrease of the effective electric field across the piezoelectric. However, the remnant polarization of the KNN ceramic is $16 \mu \mathrm{Ccm}^{-2}$ and thus, significantly lower than that of the composite, in spite of the effective field across the piezoelectric layer being lower in the latter case. This is a surprising result that requires further investigation, but that might be related to some domain reorientation effect under the compressive stresses imposed across the KNN by the two CFO layers. An enhancement of remnant polarization as a result of compressive stress is a well known phenomenon in 

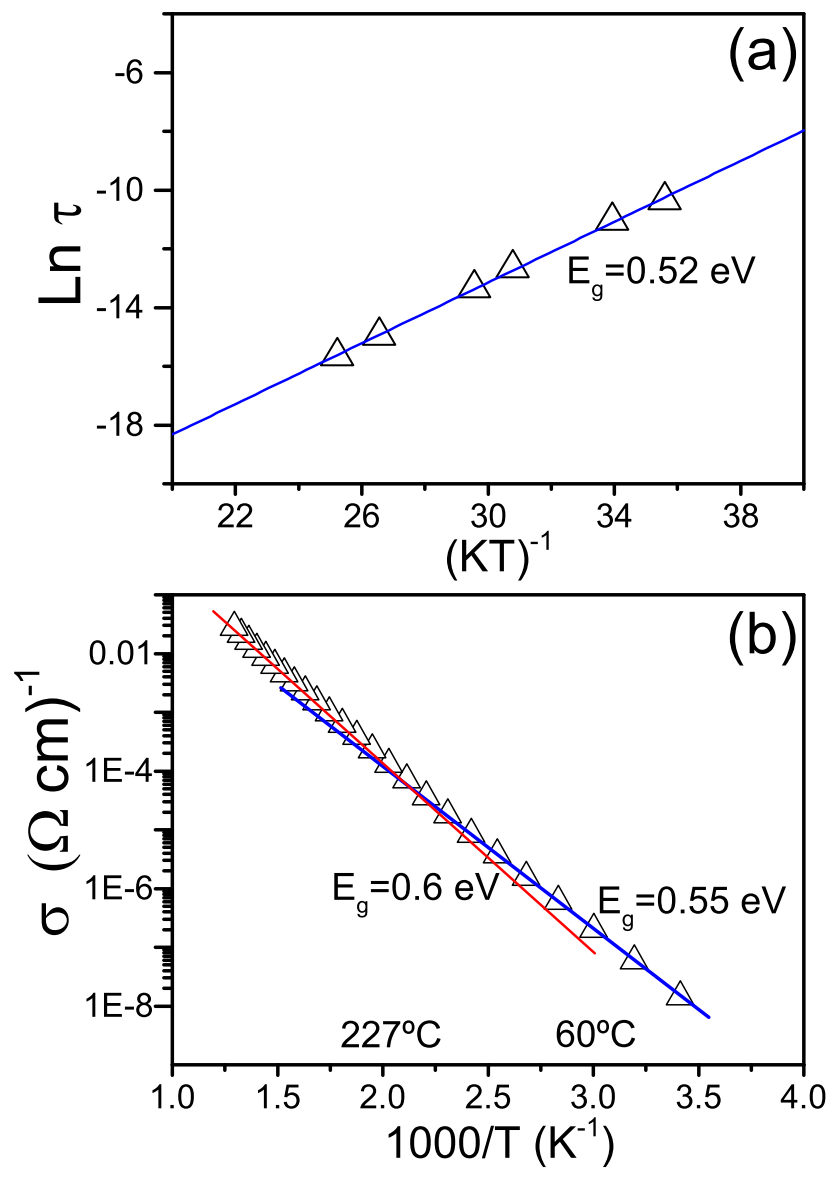

Fig. 5. Arrhenius plots for (a) the characteristic relaxation time of the intermediate temperature range, Maxwell-Wagner type dielectric relaxation of the $\mathrm{CFO} / \mathrm{KNN} / \mathrm{CFO}$ three-layer structure, and (b) the dc conductivity of a CFO ceramic analogously processed.

thin film technology [35]. It is worth remarking that ferroelectric hysteresis loops for KNN are far from saturation at $4 \mathrm{kVmm}^{-1}$ (not shown here), unlike those of the composite.

Ceramic composites were poled with $5 \mathrm{kVmm}^{-1}$ for 15 min at room temperature, which resulted in a $d_{33}$ piezoelectric coefficient of $17 p \mathrm{CN}^{-1}$. Hot poling was not possible because of non-negligible conduction, and higher elec- 


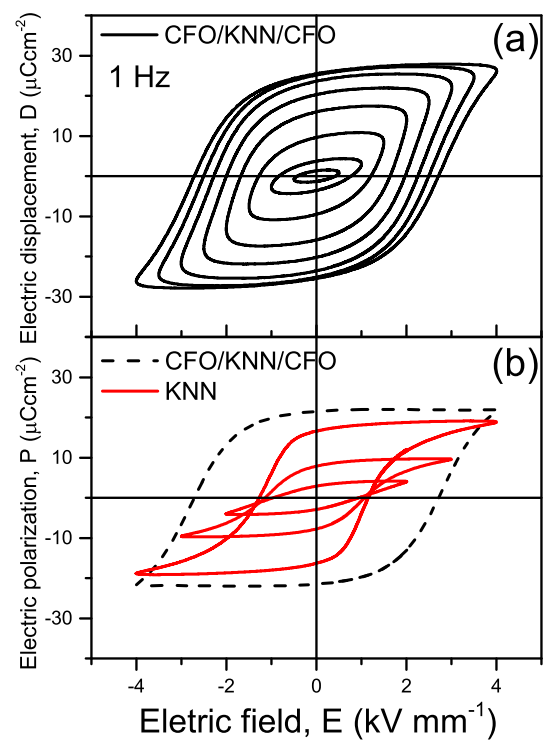

Fig. 6. Ferroelectric hysteresis loops for (a) a $\mathrm{CFO} / \mathrm{KNN} / \mathrm{CFO}$ three-layer structure, and (b) a KNN ceramic, both processed by hot pressing at $1000{ }^{\circ} \mathrm{C}$.

tric fields resulted in dielectric breakdown. This figure has to be compared with a value of $72 p \mathrm{CN}^{-1}$ for the $\mathrm{KNN}$ ceramic poled with $4 \mathrm{kVmm}^{-1}$ at 100 ${ }^{\circ} \mathrm{C}$. The reason of the reduced composite value is not clear, especially because a lower poling level cannot be assumed according to the ferroelectric hysteresis loops. Nevertheless, it is a common result in composites [20, 34, 36].

The bias magnetic field dependence of the transverse magnetoelectric coefficient $\alpha_{31}^{E}$ for composite three-layer structures is shown in Fig. 7. The effect of microcracking caused by the early removal of the pressure during cooling is illustrated by comparing the results of an optimized material with one, for which pressure was released at $300{ }^{\circ} \mathrm{C}$. Note the decrease of the maximum magnetoelectric coefficient, accompanied by a distinctive increase of the bias field for maximum response as a result of microcracking. Actu- 
ally, apparently anomalous bias field for maximum response can be taken as an indication of microcrack formation and thus, of degraded response. A maximum magnetoelectric coefficient of $1.45 \mathrm{mVcm}^{-1} \mathrm{Oe}^{-1}$ was obtained at a bias field of $1.9 \mathrm{kOe}$ under optimized processing. This value must be taken as a reference to assess response enhancement after the introduction of KNN and CFO modifications with increased piezoelectricity and biased piezomagnetism, respectively.

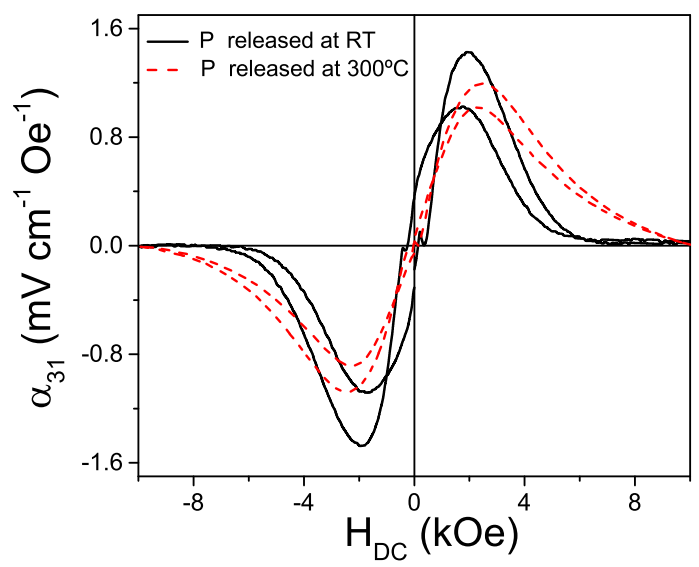

Fig. 7. Magnetoelectric coefficients of $\mathrm{CFO} / \mathrm{KNN} / \mathrm{CFO}$ three-layer structures processed by hot pressing at $1000{ }^{\circ} \mathrm{C}$.

\section{3. $\left(K_{0.5} N a_{0.5}\right)_{1-x} L i_{x} \mathrm{Nb}_{1-y} \mathrm{Ta}_{y} \mathrm{O}_{3} / \mathrm{CoFe}_{1.85} \mathrm{Ga}_{0.15} \mathrm{O}_{4}$ layered composites}

Like the case of $\mathrm{KNN} / \mathrm{CFO}$ layered composites, optimized three-layer $\mathrm{CoFe}_{1.85} \mathrm{Ga}_{0.15} \mathrm{O}_{4} / \quad\left(\mathrm{K}_{0.5} \mathrm{Na}_{0.5}\right)_{1-x} \mathrm{Li}_{x} \mathrm{Nb}_{1-y} \mathrm{Ta}_{y} \mathrm{O}_{3} / \mathrm{CoFe}_{1.85} \mathrm{Ga}_{0.15} \mathrm{O}_{4}$ structures were only obtained by hot pressing if pressure was maintained all along the final cooling step down to room temperature.

A scanning electron microscopy image of an interface for an optimized $\mathrm{CoFe}_{1.85} \mathrm{Ga}_{0.15} \mathrm{O}_{4} /\left(\mathrm{K}_{0.5} \mathrm{Na}_{0.5}\right)_{0.965} \mathrm{Li}_{0.035} \mathrm{Nb}_{0.8} \mathrm{Ta}_{0.2} \mathrm{O}_{3} / \mathrm{CoFe}_{1.85} \mathrm{Ga}_{0.15} \mathrm{O}_{4}$ three- 
layer structure processed at $1000{ }^{\circ} \mathrm{C}$ is shown in Fig. 8, along with images of the ceramic microstructure of the piezoelectric and magnetostrictive oxides. Analogously to $\mathrm{CFO} / \mathrm{KNN} / \mathrm{CFO}$ structures, high quality interfaces free of microstructural defects were obtained. However, an apparently modified very thin region of $\sim 1.5 \mu \mathrm{m}$ was found in the piezoelectric layer next to the interface with enhanced electron yield, yet microstructure is morphologically alike. This basically consists of between 1 and 3 grains that seem to have a larger average atomic number than those away from the interface. Moreover, when grains were individually inspected, a distinctive core-shell structure was revealed, so as shells also showed an enhanced electron yield. These core-shell structured grains with an average size of $\sim 1$ $\mu \mathrm{m}$ were found all across the piezoelectric layer, along with smaller, very bright grains. An analogous microstructure has already been described for $\left(\mathrm{K}_{0.5} \mathrm{Na}_{0.5}\right)_{0.96} \mathrm{Li}_{0.04} \mathrm{Nb}_{0.8} \mathrm{~T}_{0.2} \mathrm{O}_{3}$ ceramic processed by conventional sintering, and related to A- and B-cation concentration inhomogeneities, so that Taand Na-rich shells surrounded Nb- and K- rich cores, while smaller particles were Ta-rich [37]. Moreover, this chemical inhomogeneity, characteristic of samples prepared by direct mixing of alkaline carbonates and $\mathrm{Ta}$ and $\mathrm{Nb}$ oxides, could not be eliminated by prolonged high temperature annealing. Indeed, traces of the core-shell grain structure were still present in ceramics processed by conventional sintering at $1120{ }^{\circ} \mathrm{C}$ of the same powders used for the hot pressing experiments, as shown in Fig. 8f. Energy dispersive X-ray spectroscopy studies on this sample confirmed that cores were Ta-depleted as compared with shells. It is worth remarking that X-ray diffraction studies indicated single phase perovskite phase, so chemical gradients take place 
within the $\left(\mathrm{K}_{0.5} \mathrm{Na}_{0.5}\right)_{1-x} \mathrm{Li}_{x} \mathrm{Nb}_{1-y} \mathrm{Ta}_{y} \mathrm{O}_{3}$ system.

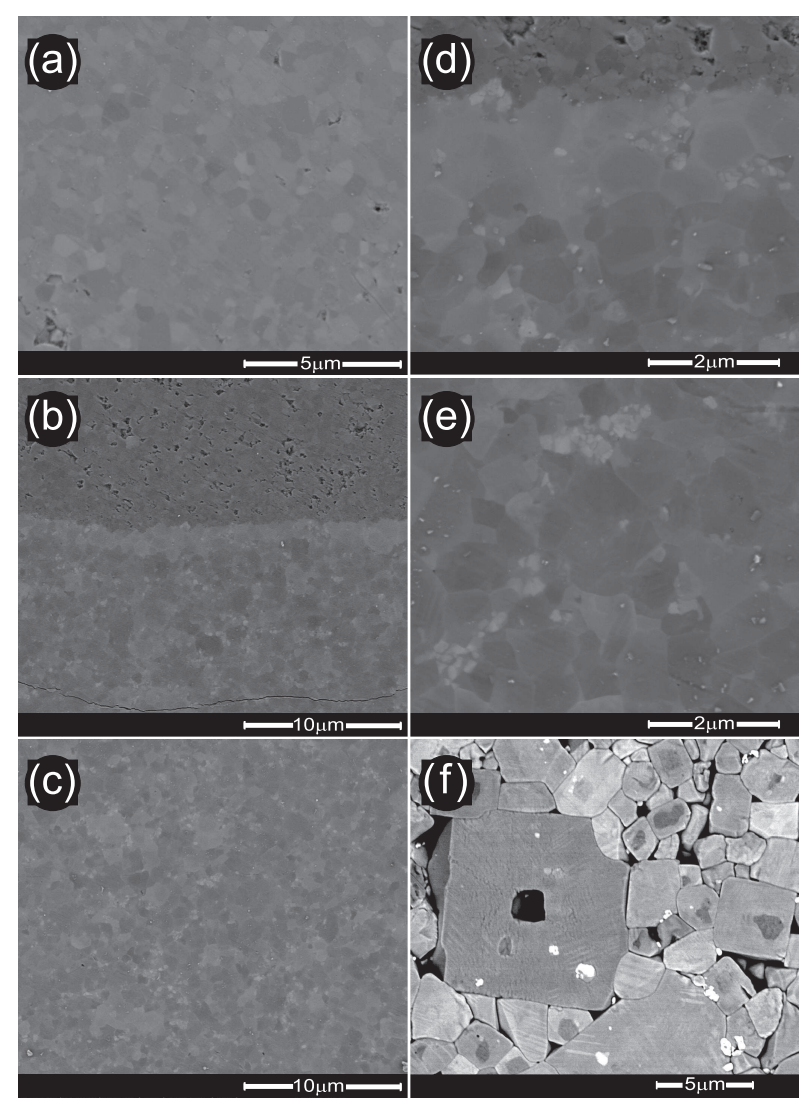

Fig. 8. Scanning electron microscopy images (a-e) across a L3.5T20/CFG15 layered composite processed by hot pressing at $1000{ }^{\circ} \mathrm{C}$ : (a) CFG15 microstructure, (b,d) CFG15/L3.5T20 interface, (c,e) L3.5T20 microstructure, and (f) of a L3.5T20 ceramic conventionally sintered at $1120{ }^{\circ} \mathrm{C}$.

This chemical inhomogeneity reflected itself in the electrical properties. Results are shown in Fig. 9, 10 and 11, where the properties of composite three-layer structures are compared with those of KNLNT piezoelectric ceramics analogously processed. The temperature and frequency dependences of the relative permittivity of a CFG15/L3.5T20/CFG15 layered structure 
processed at $1100{ }^{\circ} \mathrm{C}$ is compared in Fig. 9 with that of a L3.5T20 ceramic. The characteristic dielectric anomaly associated with the ferroelectric transition at $\sim 340{ }^{\circ} \mathrm{C}$ is easily identified in the response of the piezoceramic, and also in that of the composite at the same temperature. However, this is not so for the dielectric anomaly related to the polymorphic phase transition between the tetragonal and orthorhombic ferroelectric phases that is expected to have been shifted down, close to room temperature in relation to KNN. This is most probably a consequence of its depletion and broadening as a consequence of the discussed chemical inhomogeneity. Indeed, a distinctive high temperature shoulder is observed above the ferroelectric transition temperature for both the composite and the piezoceramic. This additional anomaly takes place at $\sim 420{ }^{\circ} \mathrm{C}$, which is the temperature of the ferroelectric transition for KNN as shown in the previous section. This must be associated with the core-shell structure and actually, it suggests cores to be KNN surrounded by KNLNT shells. Note that the relative height of the two anomalies evolve with temperature as shown in the inset of Fig. 9a, so that the height of the high temperature shoulder decreases as the hot pressing temperature increases from $1000^{\circ} \mathrm{C}$ up to $1100{ }^{\circ} \mathrm{C}$. This is observed for the composites and for the ceramics, and it does not only depend on the initial Ta content, but also on the Li one. This is illustrated in the inset of Fig. 9b, where the temperature dependence of permittivity for a L4T20 ceramic is compared with that for the L3.5T20 one processed at the same temperature. An increase of the relative height of the high temperature shoulder with the Li content can be clearly seen. Therefore, chemical inhomogeneity decreases with the increase of the hot pressing temperature, and also by decreasing 
the $\mathrm{Ta}$ and $\mathrm{Li}$ contents, yet it is not possible to make it disappear in the compositional range selected, at temperatures up to $1100{ }^{\circ} \mathrm{C}$.

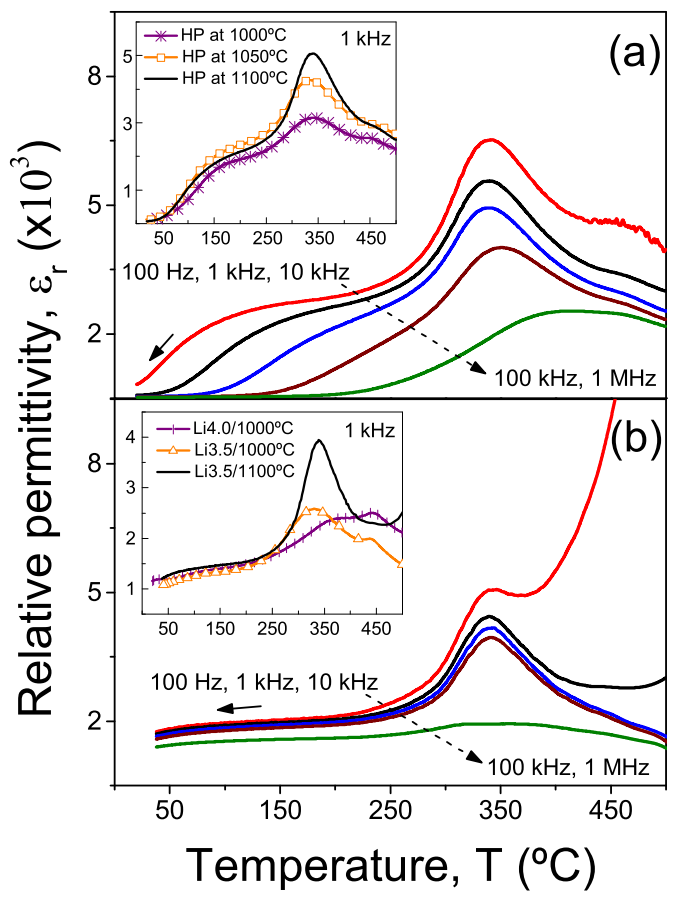

Fig. 9. Temperature and frequency dependences of the relative permittivity of (a) a CFG15/L3.5T20/CFG15 three-layer structure, and (b) a L3.5T20 ceramic, both processed by hot pressing at $1100{ }^{\circ} \mathrm{C}$. Inset in (a) shows permittivity at $1 \mathrm{kHz}$ for composite threelayer structures processed at increasing temperatures, while inset in (b) shows the permittivity for piezoceramics with increasing Li content.

Corresponding loss tangent values are given in Fig. 10. Note the presence of the Maxwell-Wagner type relaxation for the composite three-layer structure, and its absence in the piezoceramic, as already described in the case of the reference composites, and as expected from the different conductivities of the two oxides.

Room temperature ferroelectric hysteresis loops for the composite 


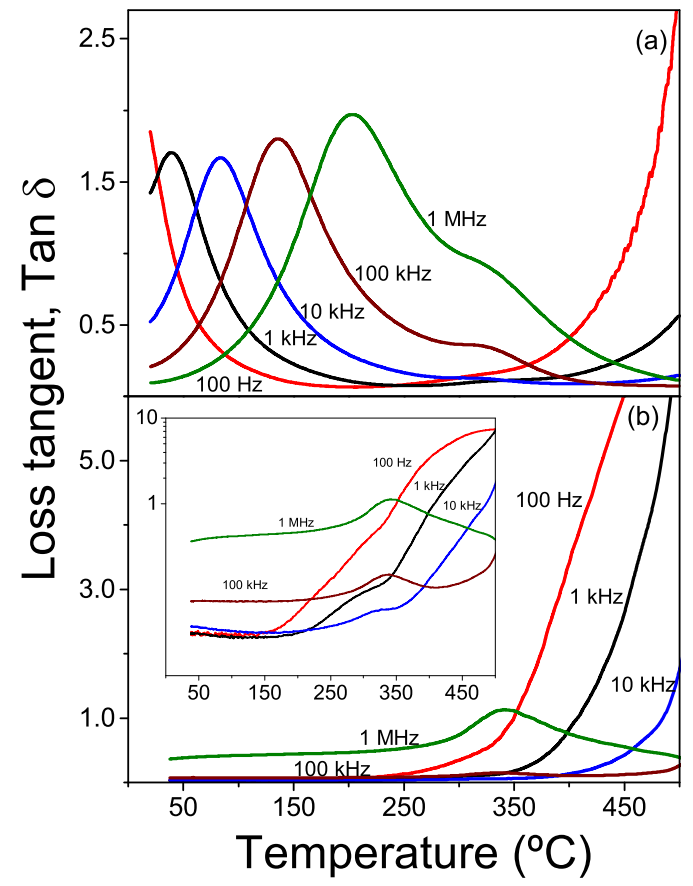

Fig. 10. Temperature and frequency dependences of the loss tangent of (a) a CFG15/L3.5T20/CFG15 three-layer structure, and (b) a L3.5T20 ceramic, both processed by hot pressing at $1100{ }^{\circ} \mathrm{C}$. Low temperature dispersion is highlighted in the inset for the piezoceramic.

CFG15/L3.5T20/CFG15 layered structure processed at $1100{ }^{\circ} \mathrm{C}$, and for the analogously processed KNLNT piezoceramic are shown in Fig. 11. Samples withstood larger electric fields than the $\mathrm{CFO} / \mathrm{KNN} / \mathrm{CFO}$ and $\mathrm{KNN}$ reference ones, and an apparent saturation of remnant polarization $P_{R}$ was attained for an electric field $E_{m}$ of $6 \mathrm{kVmm}^{-1}$. Respective values of $P_{R}$ and coercive field $E_{C}$ of $23 \mu \mathrm{Ccm}^{-2}$ and $3.5 \mathrm{kVmm}^{-1}$ were found in the case of the composite. Coercive field is significantly higher than that of the KNLNT ceramic, which was $2.0 \mathrm{kVmm}^{-1}$. This effect was already described for the $\mathrm{CFO} / \mathrm{KNN} / \mathrm{CFO}$ structures, and it is thus associated with the presence of 
the CFG15 two layers in series with the KNLNT, which results in a decrease of the effective electric field within the piezoelectric. Similarly, the remnant polarization of the KNLNT/CFG layered composite was significantly higher than that of the KNLNT ceramic, which was only $17 \mu \mathrm{Ccm}^{-2}$. This has already been proposed to relate to some domain reorientation effects as a consequence of the compressive stress imposed by the two CFG layers across the KNLNT one.

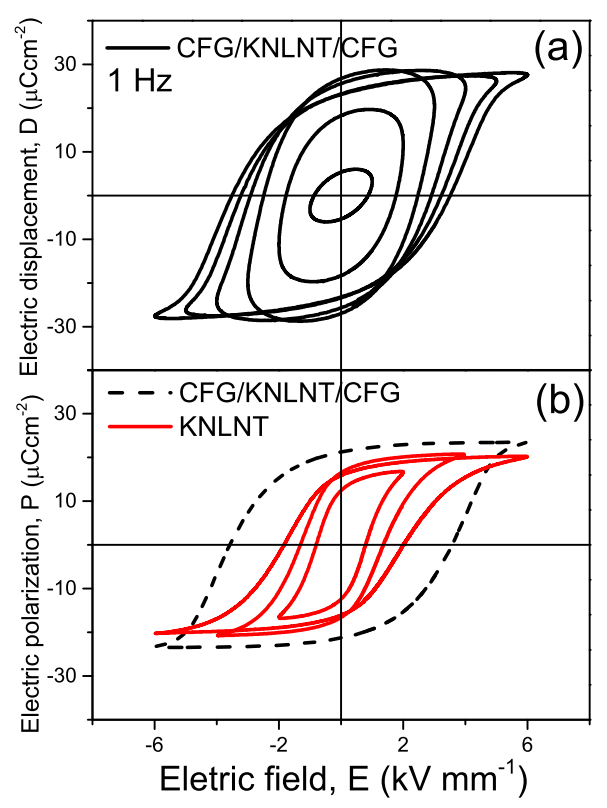

Fig. 11. Ferroelectric hysteresis loops for (a) a CFG15/KNLNT/CFG15 three-layer structure, and (b) a KNLNT ceramic, both processed by hot pressing at $1100{ }^{\circ} \mathrm{C}$.

Ceramic composites were poled with $6 \mathrm{kVmm}^{-1}$ for 15 min at room temperature, which resulted in a $d_{33}$ piezoelectric coefficient that increased with the hot pressing temperature for a given composition. For instance, values of 37, 40 and $63 p \mathrm{CN}^{-1}$ were obtained for composite CFG15/L3.5T20/CFG15 structures hot pressed at 1000,1050 and $1100{ }^{\circ} \mathrm{C}$, respectively. This figure 
has to be compared with a value of $\sim 130 \mathrm{pCN}^{-1}$ for piezoceramics analogously processed. Lower values were obtained with L4T20- and L4T15based composites that showed piezoelectric coefficients of 30 and $26 p \mathrm{CN}^{-1}$, to be compared with values of 83 and $100 p \mathrm{CN}^{-1}$ for piezoceramics. Phenomenology is again analogous to that of the reference materials, and reduced piezoelectric coefficients are consistently measured in the layered composites.

The bias magnetic field dependence of the transverse magnetoelectric coefficient $\alpha_{31}^{E}$ for composite three-layer structures is shown in Fig. 12. The magnetoelectric response of a number of composites with different composition, processed at $1000{ }^{\circ} \mathrm{C}$ is given in Fig. 12a. Maximum response was obtained for the CFG15/L3.5T20/CFG15 structure that presented a maximum magnetoelectric coefficient of $2.9 \mathrm{mVcm}^{-1} \mathrm{Oe}^{-1}$ at a bias field of 1.4 kOe. Coefficients increased with the temperature of the hot pressing, so that CFG15/L3.5T20/CFG15 processed at $1100{ }^{\circ} \mathrm{C}$ had a maximum magnetoelectric coefficient of $8.3 \mathrm{mVcm}^{-1} \mathrm{Oe}^{-1}$ at a bias field of $0.95 \mathrm{kOe}$.

\subsection{Final considerations}

The introduction of KNN and CFO modified compositions with increased piezoelectricity and biased piezomagnetism resulted in an increase of the maximum magnetoelectric coefficient; from 1.45 up to $8.3 \mathrm{mVcm}^{-1} \mathrm{Oe}^{-1}$, and a reduction of the bias field for maximum response; from 1.9 down to $0.95 \mathrm{kOe}$, as intended. However, figures are somehow smaller than expected, which is most probably a consequence of the core-shell grained microstructure. This is confirmed by the distinctive increase of response with the hot pressing temperature, and with the decrease of Li content in the piezoelectric composition that directly correlates with the decrease in chemical inhomo- 


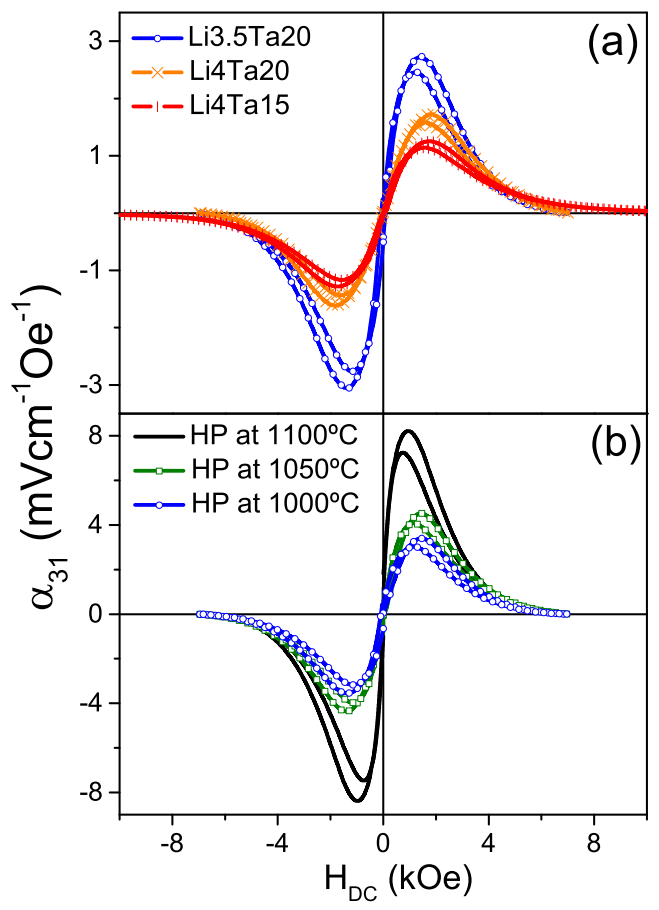

Fig. 12. Magnetoelectric coefficients of CFG15/KNLNT/CFG15 three-layer structures (a) with different KNLNT compositions, processed by hot pressing at $1000{ }^{\circ} \mathrm{C}$, and (b) with L3.5T20, processed by hot pressing at increasing temperature.

geneity. Indeed, the role of this distinctive microstructure in degrading the piezoelectric performance of KNLNT piezoceramics has already been discussed [37].

This phenomenon is characteristic of samples prepared by direct mixing of alkaline carbonates and $\mathrm{Ta}$ and $\mathrm{Nb}$ oxides, as it is the case here, and cannot be completely eliminated by prolonged high temperature annealing, yet it can be minimized. As a matter of fact, the L3.5T20 piezoelectric ceramic of Fig. 8f that had been conventionally sintered at $1120^{\circ} \mathrm{C}$, and which only presented traces of the core-shell grained microstructure, attained a $d_{33}$ 
piezoelectric coefficient of $\sim 230 p \mathrm{CN}^{-1}$, to be compared with $130 p \mathrm{CN}^{-1}$ for a sample hot pressed at $1100{ }^{\circ} \mathrm{C}$. Optimized KNLNT compositions are those, for which the ferroelectric polymorphic phase transition between the tetragonal and orthorhombic phases has been shifted down to room temperature by Ta and Li substitutions, so even small local deviations from the average composition caused by stabilized gradients have a strong effect on the piezoelectric response and thus, on the magnetoelectric one of any layered structure containing them. Besides, additional compositional deviations have been found in the specific system here studied, next to the KNLNT/CFG interface. This is most probably associated with interface-stress induced diffusion effects, and must cause an additional reduction of the magnetoelectric response.

Therefore, the magnetoelectric response of the environmentally friendly KNLNT/CFG layered composites is limited by the chemical inhomogeneity within the piezoelectric layers, which can be reduced by increasing processing temperature. However, this cannot be done without triggering alkali volatilization and chemical reactions at, and interdiffusion across the piezoelectric/magnetostrictive interfaces. A trade-off thus must be reached. An alternative might be the use of non-conventional synthesis methods also for KNLNT to improve chemical homogeneity at the powder level, while maintaining the high reactivity required for co-sintering. In ref. [37], pre-reaction of the $\mathrm{Nb}_{2} \mathrm{O}_{5}$ and $\mathrm{Ta}_{2} \mathrm{O}_{5}$ precursor oxides was shown to be an effective means of avoiding the formation of the core-shell grained microstructures with a direct effect on piezoelectric properties. Wet chemistry and mechanochemical activation techniques also deserve attention [38, 39]. 
A second alternative could be to concentrate in Ta-free KNNbased compositions, like $\left(\mathrm{K}_{0.5} \mathrm{Na}_{0.5}\right)_{1-x} \mathrm{Li}_{x} \mathrm{O}_{3}$. This system can also show quite high piezoelectric coefficients [40], and an $\alpha_{31}^{E}$ as high as $\sim 285 \mathrm{mVcm}^{-1} \mathrm{Oe}^{-1}$ has been recently reported for composite $\mathrm{Li}_{0.058}\left(\mathrm{Na}_{0.535} \mathrm{~K}_{0.48}\right)_{0.942} \mathrm{NbO}_{3} / \mathrm{Co}_{0.6} \mathrm{Zn}_{0.4} \mathrm{Fe}_{1.7} \mathrm{Mn}_{0.3} \mathrm{O}_{4}$ layered structures [41].

\section{Summary and conclusions}

Dense, high quality $\mathrm{K}_{0.5} \mathrm{Na}_{0.5} \mathrm{NbO}_{3} / \mathrm{CoFe}_{2} \mathrm{O}_{4}$ layered composites with defect-free interfaces can be obtained by hot pressing at a temperature as low as $1000{ }^{\circ} \mathrm{C}$, if highly reactive $\mathrm{CoFe}_{2} \mathrm{O}_{4}$ powders are used. No indication of chemical reactions at, or interdiffusion across interfaces is found, while alkali volatilization is effectively suppressed at this temperature. A complete electrical, piezoelectric and magnetoelectric characterization has been carried out that revealed a number of composite effects. The temperature and frequency dependences of permittivity showed the presence of a distinctive Maxell-Wagner type relaxation as a result of the different conductivity of the piezoelectric and magnetostrictive oxides. Room temperature ferroelectric hysteresis loops presented enhanced remnant polarization as compared with piezoceramics. This suggests the presence of residual compressive stresses within the piezoelectric layer, which is advantageous for the composite poling. However, reduced $d_{33}$ piezoelectric charge coefficients are measured. A maximum magnetoelectric coefficient of $1.45 \mathrm{mVcm}^{-1} \mathrm{Oe}^{-1}$ under a bias field of $1.9 \mathrm{kOe}$ is found, which reflects the respective, relatively low piezoresponse of the two phases. 
Dense, crack-free $\left(\mathrm{K}_{0.5} \mathrm{Na}_{0.5}\right)_{1-x} \mathrm{Li}_{x} \mathrm{Nb}_{1-y} \mathrm{Ta}_{y} \mathrm{O}_{3} / \mathrm{CoFe}_{2-x} \mathrm{Ga}_{x} \mathrm{O}_{4}$ layered composites incorporating phases with enhanced piezoresponse have also been obtained by the same procedure, yet piezoelectric layers develop a core-shell grained microstructure in this case, with a direct effect on the final magnetoelectric response. Chemical inhomogeneity decreases with the $\mathrm{Ta}$ and $\mathrm{Li}$ contents and also when the hot pressing temperature is increased, yet it is still present at $1100{ }^{\circ} \mathrm{C}$ for the compositional range investigated. A maximum magnetoelectric coefficient of $8.3 \mathrm{mVcm}^{-1} \mathrm{Oe}^{-1}$ under a bias field of $0.85 \mathrm{kOe}$ has been attained.

\section{Acknowledgements}

Research funded by Brazilian PVE/CAPES (process 88881.030500/201301) and grant \#2013/00134-7 São Paulo Research Foundation (FAPESP) and by Spanish MINECO through project MAT2014-58816-R.

\section{References}

[1] M. Liu, O. Obi, J. Lou, Y. Chen, Z. Cai, S. Stoute, M. Espanol, M. Lew, X. Situ, K. S. Ziemer, V. G. Harris, N. X. Sun, Adv. Funct. Mater. 19 (2009) 1826-1831. doi:10.1002/adfm.200801907.

[2] Y. Wang, D. Gray, D. Berry, J. Gao, M. Li, J. Li, D. Viehland, Adv. Mater. 23 (2011) 4111-4114. doi:10.1002/adma.201100773.

[3] R. C. O'Handley, J. K. Huang, D. C. Bono, J. Simon, IEEE Sens. J. 8 (2008) 57-62. doi:10.1109/JSEN.2007.912899. 
[4] J. Han, J. Hu, Y. Yang, Z. Wang, S. X. Wang, J. He, IEEE Trans. Ind. Electron. 62 (2015) 4398-4407. doi:10.1109/TIE.2014.2383992.

[5] C.-W. Nan, M. I. Bichurin, S. Dong, D. Viehland, G. Srinivasan, J. Appl. Phys. 103 (2008) 031101. doi:10.1063/1.2836410.

[6] J. Ma, J. Hu, Z. Li, C.-W. Nan, Adv. Mater. 23 (2011) 1062-1087. doi:10.1002/adma.201003636.

[7] N. Ortega, A. Kumar, J. F. Scott, R. S. Katiyar, J. Phys.: Condens. Matter 27 (2015) 504002. doi:10.1088/0953-8984/27/50/504002.

[8] G. Srinivasan, E. T. Rasmussen, J. Gallegos, R. Srinivasan, Y. I. Bokhan, V. M. Laletin, Phys. Rev. B 64 (2001) 214408. doi:10.1103/PhysRevB.64.214408.

[9] R. A. Islam, Y. Ni, A. G. Khachaturyan, S. Priya, J. Appl. Phys. 104 (2008) 044103. doi:10.1063/1.2966597.

[10] Y. Zhou, Y. Yan, S. Priya, Appl. Phys. Lett. 104 (2014) 232906. doi:10.1063/1.4883492.

[11] J. Rödel, W. Jo, K. T. P. Seifert, E.-M. Anton, T. Granzow, D. Damjanovic, J. Am. Ceram. Soc. 92 (2009) 1153-1177. doi:10.1111/j.15512916.2009.03061.x.

[12] J. Rödel, K. G. Webber, R. Dittmer, W. Jo, M. Kimura, D. Damjanovic, J. Eur. Ceram. Soc. 35 (2015) 1659 - 1681. doi:10.1016/j.jeurceramsoc.2014.12.013. 
[13] S.-T. Zhang, A. B. Kounga, E. Aulbach, H. Ehrenberg, J. Rödel, Appl. Phys. Lett. 91 (2007) 112906. doi:10.1063/1.2783200.

[14] A. Moosavi, M. A. Bahrevar, A. R. Aghaei, P. Ramos, M. Algueró, H. Amorín, J. Phys. D: Appl. Phys. 47 (2014) 055304. doi:10.1088/0022$3727 / 47 / 5 / 055304$.

[15] S. Liu, L. Deng, S. Yan, H. Luo, L. Yao, L. He, Y. Li, M. Wu, S. Huang, J. Appl. Phys. 122 (2017) 034103. doi:10.1063/1.4994172.

[16] W. Liu, X. Ren, Phys. Rev. Lett. 103 (2009) 257602. doi:10.1103/PhysRevLett.103.257602.

[17] J. Rani, V. K. Kushwaha, J. Kolte, C. Tomy, J. Alloys. Comp. 696 (2017) 266 - 275. doi:https://doi.org/10.1016/j.jallcom.2016.11.269.

[18] Y. Saito, H. Takao, T. Tani, T. Nonoyama, K. Takatori, T. Homma, T. Nagaya, M. Nakamura, Nature 432 (2004) 84-87. doi:10.1038/nature03028.

[19] S.-C. Yang, C.-W. Ahn, K.-H. Cho, S. Priya, J. Am. Ceram. Soc. 94 (2011) 3889-3899. doi:10.1111/j.1551-2916.2011.04580.x.

[20] Y. Lin, J. Zhang, H. Yang, T. Wang, J. Alloys. Comp. 692 (2017) 86 94. doi:10.1016/j.jallcom.2016.09.009.

[21] H. Yang, G. Zhang, G. Hai, X. Xiang, J. Alloys. Comp. 646 (2015) 1104 - 1108. doi:10.1016/j.jallcom.2015.06.058. 
[22] Y. Wang, Y. Pu, Y. Tian, X. Li, Z. Wang, Y. Shi, J. Zhang, G. Zhang, J. Alloys. Comp. 696 (2017) 1307 - 1313. doi:10.1016/j.jallcom.2016.11.242.

[23] E. Ramana, F. Figueiras, M. P. F. Graça, M. A. Valente, Dalton Trans. 43 (2014) 9934-9943. doi:10.1039/c4dt00956h.

[24] M. Naveed-Ul-Haq, V. V. Shvartsman, S. Salamon, H. Wende, H. Trivedi, A. Mumtaz, D. C. Lupascu, Sci. Rep. 6 (2016) 32164. doi:10.1038/srep32164.

[25] R. Rakhikrishna, J. Isaac, J. Philip, Ceram. Int. 43 (2017) 664 - 671. doi:10.1016/j.ceramint.2016.09.212.

[26] J.-F. Li, K. Wang, F.-Y. Zhu, L.-Q. Cheng, F.-Z. Yao, J. Am. Ceram. Soc. 96 (2013) 3677-3696. doi:10.1111/jace.12715.

[27] S. H. Song, C. C. H. Lo, S. J. Lee, S. T. Aldini, J. E. Snyder, D. C. Jiles, J. Appl. Phys. 101 (2007) 09C517. doi:10.1063/1.2712941.

[28] G. Srinivasan, C. P. DeVreugd, C. S. Flattery, V. M. Laletsin, N. Paddubnaya, Appl. Phys. Lett. 85 (2004) 2550-2552. doi:10.1063/1.1795365.

[29] R. Gao, X. Chu, Y. Huan, X. Wang, L. Li, Mat. Lett. 123 (2014) 242 245. doi:10.1016/j.matlet.2014.03.027.

[30] E. Hollenstein, M. Davis, D. Damjanovic, N. Setter, Appl. Phys. Lett. 87 (2005) 182905. doi:10.1063/1.2123387.

[31] J. Fu, W. S. Rosa, J. C. M'Peko, M. Algueró, M. Venet, Phys. Lett. A 380 (2016) 1788 - 1792. doi:10.1016/j.physleta.2016.03.024. 
[32] A. Muhammad, R. Sato-Turtelli, M. Kriegisch, R. Grössinger, F. Kubel, T. Konegger, J. Appl. Phys. 111 (2012) 013918. doi:10.1063/1.3675489.

[33] Unpublished results. (2017).

[34] H. Amorín, M. Algueró, R. D. Campo, E. Vila, P. Ramos, M. Dollé, Y. Romaguera-Barcelay, J. P. D. L. Cruz, A. Castro, Sci. Technol. Adv. Mater. 16 (2015) 016001. doi:10.1088/1468-6996/16/1/016001.

[35] M. Algueró, M. L. Calzada, A. J. Bushby, M. J. Reece, Appl. Phys. Lett. 85 (2004) 2023-2025. doi:10.1063/1.1787594.

[36] J. Zhai, N. Cai, Z. Shi, Y. Lin, C.-W. Nan, J. Appl. Phys. 95 (2004) 5685-5690. doi:10.1063/1.1699499.

[37] Y. Wang, D. Damjanovic, N. Klein, E. Hollenstein, N. Setter, J. Am. Ceram. Soc. 90 (2007) 3485-3489. doi:10.1111/j.1551-2916.2007.01962.x.

[38] C. Pithan, Y. Shiratori, J. Dornseiffer, F.-H. Haegel, A. Magrez, R. Waser, J. Cryst. Growth 280 (2005) 191 - 200. doi:10.1016/j.jcrysgro.2005.03.038.

[39] T. Rojac, M. Kosec, B. Mali, J. Holc, Sci. Sinter. 37 (2005) 61-67. doi:10.2298/SOS0501061R.

[40] J. Wu, D. Xiao, J. Zhu, Chem. Rev. 115 (2015) 2559-2595. doi:10.1021/cr5006809.

[41] H. Yang, J. Zhang, Y. Lin, T. Wang, Sci. Rep. 7 (2017) 44855. doi:10.1038/srep44855, article. 